\title{
Enfoques archivísticos en la obra de Paul Otlet
}

\author{
Leomar José Montilla Peña \\ Universidad Politécnica Territorial de Lara Andrés Eloy Blanco, UPTAEB - Venezuela
}

\section{ANALISE}

\begin{abstract}
Resumen
Se presenta un estudio bibliométrico de El Tratado de Documentación de Paul Otlet donde el objetivo fue analizar los enfoques del área archivística registrados en él. Para la realización de este estudio, se utilizaron el método descriptivo y el método de palabras asociadas. Se aplicó un muestreo estadístico longitudinal para los periodos1898 a 1933, porque en él se publicaron los tres primeros manuales científicos de la Archivística clásica. Los resultados revelaron que existe un total de 10 referencias relacionadas con la archivística, siendo Otlet el autor más mencionado, que posee más citaciones y referencias sobre esta área. Las temáticas más utilizadas por Otlet sobre la ciencia archivística para su fundamentación discursiva fueron: métodos de organización y documentos administrativos. Del análisis se concluye que los enfoques archivísticos registrados en El Tratado de Documentación poseen centralidad y baja densidad.
\end{abstract}

Palabras clave

Estudio bibliométrico ; Método descriptivo ; Método de palabras asociadas ; Archivística ; El Tratado de Documentación ; Paul Otlet

\section{Archival approaches in the work of Paul Otlet}

\begin{abstract}
We present a bibliometric study of the Treaty of Documentation of Paul Otlet where the goal was to analyze approaches the archival area registered on it. For this study, used the descriptive words method and the associated words method. We applied a longitudinal statistical sampling for periods 1898 to 1933 , because he published the first three scientists manuals the classical Archives. The results revealed that there is a total of 10 references related to the archives, the author being Otlet else mentioned, it has more citations and references on this area. The topics most frequently used by Otlet on archival science for discursive reasoning were: methods of organization and administrative documents. The analysis finds that archival approaches registered in the Treaty of Documentation have centrality and low density.
\end{abstract}

Keywords

Bibliometric studies ; Descriptive method ; Associated words method , Archival ; Treaty of Documentation ; Paul Otlet

\section{Introducción}

Desde su aparición en 1934, El Tratado de Documentación de Paul Otlet se ha constituido en elemento primordial y en herramienta valiosa para la investigación de las ciencias que estudian la información registrada, en especial para la Ciencias de la Información debido a su gran aporte para gestionar todos los "recursos de información en cualquier contexto aplicable..." (Bucklan, 2008, p.8, traducido por el autor). A partir de este hecho se considero de gran importancia realizar un estudio bibliométrico, con el objetivo de determinar que enfoques de la "archivística clásica" (Thomassen, 1999) se encuentran registrados en esta obra. Hasta ahora, no se han realizado trabajo bibliométrico como este que permitan representar tal dimensión.

La estructura del trabajo esta divido en tres partes. La primera describe los materiales y métodos que se utilizaron en la investigación. La segunda describe los resultados encontrados en El Tratado de Documentación 
y el análisis de estos. La última contiene las conclusiones a la que se llegó de acuerdo a los resultados obtenidos.

\section{Materiales y métodos}

El trabajo experimental se desarrolló a partir del análisis de El Tratado de Documentación de Paul Otlet, por el hecho de ser este el primer tratado metacientífico en agrupar las ciencias que estudian la información registrada, donde la Archivística es una de ellas, encontrándose en su período de desarrollo clásico. Ello permitió realizar un análisis para determinar la repercusión o importancia de las referencias realizadas y palabras asociadas sobre la temática Archivística aparecida en esta obra.

La variable estudiada fue los enfoques archivísticos presentes en El Tratado de Documentación, para ello se realizó un muestreo estadístico longitudinal comprendido en el periodo que va desde 1898 a 1933. Este rango de tiempo se justifica porque en él se publicaron los tres primeros manuales científicos de la Archivística clásica, hasta que se publica la majestuosa obra de la documentación en 1934. Para la sistematización y análisis de los diversos aspectos de la Archivística se utilizó el método descriptivo, a partir de dos tipos de análisis, el primero de carácter descriptivo bibliométrico, consistió en revisar, resumir, identificar y ordenar la información obtenida sobre la temática Archivística a través de la lectura, y el segundo de evaluación bibliométrica sobre los datos textuales que permitió organizar, describir, resumir y determinar qué teorías, principios y métodos de la Archivística están presentes en El Tratado de Documentación.

Sin embargo, resulta importante precisar que el método de palabras asociadas fue el que permitió identificar con más regularidad la presencia de los enfoques archivísticos y para respaldarlo se empleó la frecuencia de palabras y las coocurrencias con el fin de determinar las expresiones y argumentaciones propuestas, así como la asociación de categorías y la forma del discurso, logrado de esta manera determinar la parte descriptiva y explicativa. Para alcanzar tal propósito se definieron los siguientes indicadores: el volumen de trabajos citados sobre el área Archivística, el número de citas utilizadas, el idioma de la obras referenciadas, descriptores temáticos de mayor relevancia, descriptores temáticos asociados, enfoques archivísticos encontrados, entre otros elementos, que permitieron analizar en su conjunto los datos textuales resultantes.

La hoja de cálculo Excel 2007, permitió diseñar cuatro (4) tablas y tres (3) figuras a partir de los datos obtenidos. Para el análisis social fue empleado el software UCINET y sus paquetes gráficos Pajek y NetDraw, obteniendo cuatro (4) figuras, que permiten una visualización de las relaciones asociadas, encontrando entre ellas la referencia de autores citados, la dispersión de palabras comunes con mayor frecuencia, las palabras descriptivas y la palabras asociadas, todo ello con la intención de mostrar los resultados referente a los enfoques archivísticos en El Tratado de Documentación.

\section{Resultados y discusión}

A continuación se presentan los resultados y la discusión obtenida durante esta investigación, los cuales tributan a la visualización de los enfoques archivísticos presentes en El Tratado de Documentación.

\subsection{Análisis de las obras bibliográficas utilizada en el área archivística}

La lectura de El Tratado de Documentación permitió identificar un total de 10 referencias bibliográficas relacionadas con al área Archivística, estas referencias parten desde el año de 1908 hasta 1933. Fue imposible identificar la fecha de una de las publicaciones registradas. La intervención por parte de cada una de las referencias registradas en porcentaje es bastante equilibrada, excepto en los años de 1910 y 1923 en que la diferencia se eleva a un $17 \%$ en cada uno de los casos, este fenómeno se debe a la referencia de dos manuales que tienen que ver con la organización de los documentos administrativos. Esta matematización se puede apreciar con precisión en la Tabla 1. 


\begin{tabular}{|c|c|c|c|c|c|}
\hline $\begin{array}{c}\text { Año de } \\
\text { Publicación }\end{array}$ & Autores & Título del Documento & $\begin{array}{l}\text { Tipo de } \\
\text { Documento }\end{array}$ & $\begin{array}{l}\mathrm{N}^{\circ} \\
\text { Referencia }\end{array}$ & $\%$ \\
\hline 1908 & Joseph Cuvelier & $\begin{array}{l}\text { La necesidad de pagos periódicos de documentos } \\
\text { administrativos dan los Archivos }\end{array}$ & Informe & 1 & 8 \\
\hline 1910 & $\begin{array}{l}\text { S. Muller, J. Freth y } \\
\text { R. Fruin }\end{array}$ & $\begin{array}{l}\text { Manual para la organización y descripción de los } \\
\text { archivos. Traducción de J. Cuvelier y H. Stein }\end{array}$ & Libro & 2 & 17 \\
\hline 1910 & Joseph Cuvelier & $\begin{array}{l}\text { Boletín de la Asociación de Archivistas y } \\
\text { Bibliotecarios }\end{array}$ & Boletín & 1 & 8 \\
\hline 1923 & Paul Otlet & Manual de la Documentación administrativa & Informe & 2 & 17 \\
\hline 1924 & $\begin{array}{l}\text { Paul Eugene Louis } \\
\text { Fournier }\end{array}$ & $\begin{array}{l}\text { Consejos para la clasificación y el inventario de } \\
\text { los archivos y la edición de escritos históricos }\end{array}$ & Artículo & 1 & 8 \\
\hline 1930 & Maurice Felin & En la administración local & Informe & 1 & 8 \\
\hline 1930 & $\begin{array}{l}\text { Gobierno de } \\
\text { España }\end{array}$ & Nota Oficial del Gobierno Español & $\begin{array}{l}\text { Boletín } \\
\text { Oficial }\end{array}$ & 1 & 8 \\
\hline 1930 & Paul Otlet & $\begin{array}{l}\text { Las oportunidades para las entidades } \\
\text { administrativas }\end{array}$ & Informe & 1 & 8 \\
\hline 1933 & Edwards & Servicio de Inteligencia & Informe & 1 & 8 \\
\hline$S / F$ & $\begin{array}{c}\text { Partido Político } \\
\text { Nacional de } \\
\text { Génova }\end{array}$ & $\begin{array}{l}\text { Estatutos del partido del orden político nacional } \\
\text { en Génova }\end{array}$ & Estatutos & 1 & 8 \\
\hline \multicolumn{4}{|c|}{ Total } & 12 & 100 \\
\hline
\end{tabular}

Tabla 1 - Cifra total de referencias bibliográficas y promedio de referencias del área Archivística registradas en El Tratado de Documentación

Entre los resultados encontrados en la investigación, en la Tabla 2, se puede observar que fueron referenciados 10 autores del área Archivística, entre ellos 2 autores institucionales y 8 autores independientes, donde 3 de ellos son los firmantes de un documento, predominando con mayor citación recibida Paul Otlet con un total del $25 \%$, mientras que Samuel Muller, Johan Freith, Robert Fruin y Joseph Cuvilier ostentan un 17\%, el resto de los autores citados se encuentra de manera proporcionada.

\begin{tabular}{|l|c|c|}
\hline \multicolumn{1}{|c|}{ Autor } & $N^{\circ}$ de Citas Recibidas & \% \\
\hline Edwards & 1 & 8 \\
\hline Gobierno de España & 1 & 17 \\
\hline Joseph Cuvelier & 2 & 8 \\
\hline Maurice Felin & 1 & 8 \\
\hline Partido Político Nacional de Génova & 1 & 25 \\
\hline Paul Eugene Louis Fournier & 1 & 17 \\
\hline Paul Otlet & 3 & 100 \\
\hline S. Muller, J. Freth y R. Fruin & 2 & 8 \\
\hline Total & 12 & \\
\hline
\end{tabular}

Tabla 2 - Número y promedio de citas por autores registrados del área Archivística en el Tratado de Documentación 
El número de referencias totales del área Archivística registradas en El Tratado de Documentación de acuerdo al tipo de documento, se encuentran registradas en la Figura 1, los informe casi triplican al libro, con un diferencia porcentual del $33 \%$, esta diferencia se ha de atribuir al número de informe registrados y al mayor número de citas recibidas. Por medio de este indicador también se pudo determinar que Otlet consideró otros tipos de documentos para su consumo de información bibliográfica.

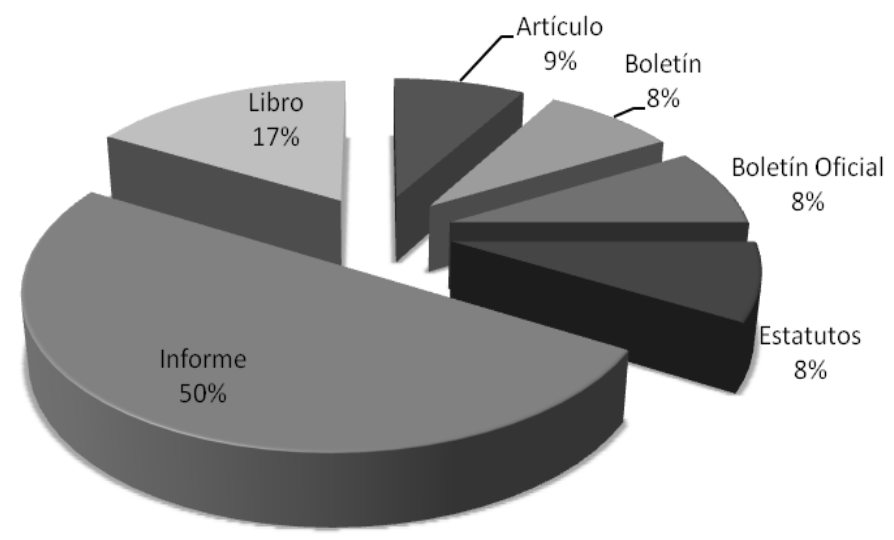

Figura 1 - Porcentaje de referencia por tipo de documento del área Archivística registrada en el Tratado de Documentación

En la Figura 2 se encuentra la evolución a lo largo del tiempo de las referencias encontradas. Llama la atención el aumento de los informes entre 1908 y 1933, percibiéndose el 55\% a favor, de acuerdo a la fracción más citada. Es importante mencionar que el documento referenciado del Partido Político Nacional de Génova no se consideró para este análisis, por no contar con su fecha exacta de publicación. Sin embargo, en los 35 años de análisis se aprecia que la producción sobre Archivística crece, es decir, la literatura sobre el tema crece al ritmo de las exigencias de las administraciones públicas y privadas durante ese periodo.

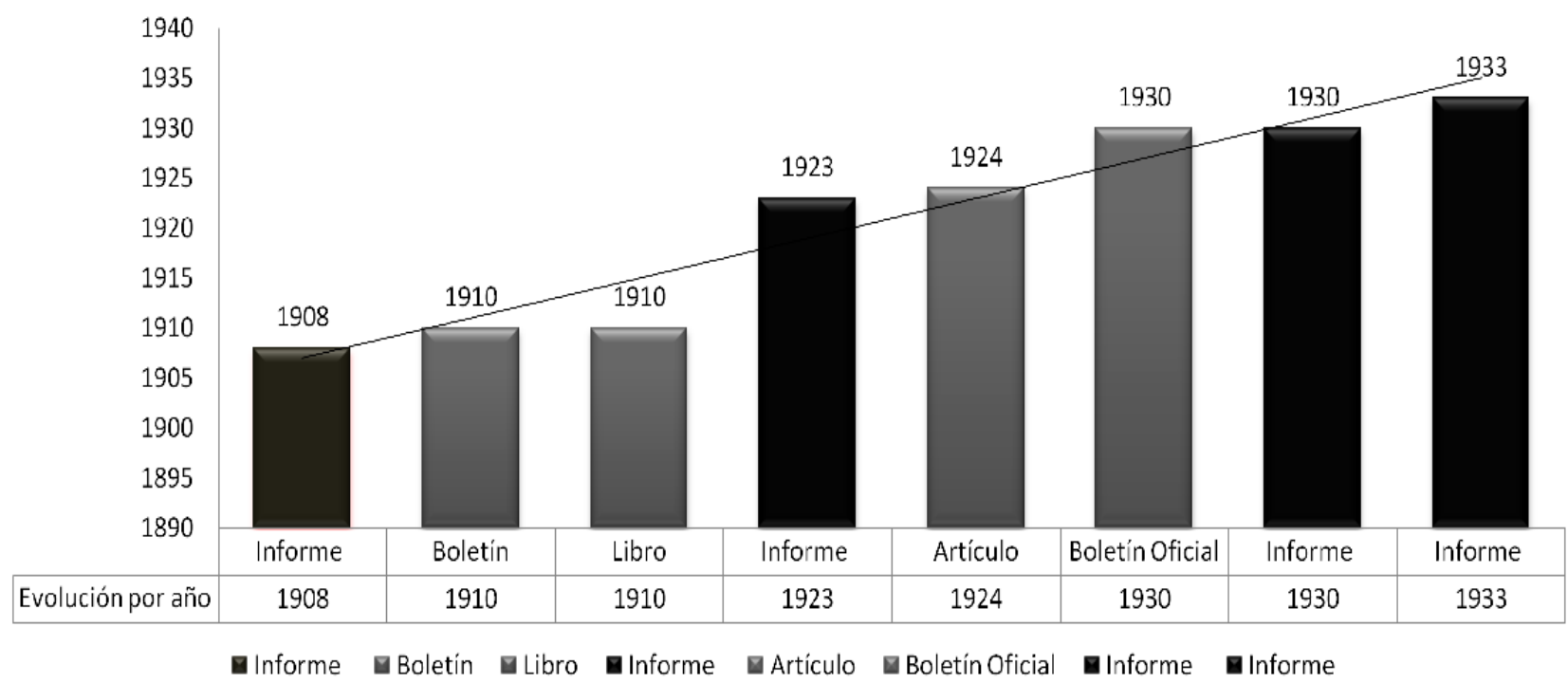

Figura 2 - Porcentaje de referencia por tipo de documento del área Archivística registrada en el Tratado de Documentación 
De acuerdo a la Ley de Bradford, el análisis de las referencias dejar ver que $83 \%$ de las citas del área Archivística realizadas por Otlet en El Tratado de Documentación, son en idioma francés y que los años de mayor referencia fueron 1910 y 1923. Ello puede ser el resultado de que el idioma francés es uno de los tres idiomas oficiales de Bélgica. Sin embargo, Otlet realizó un pequeño número de citas en italiano y español.

\begin{tabular}{lcc}
\hline \multicolumn{1}{c}{ Idioma } & $\mathbf{N}^{\circ}$ de referencia & $\%$ \\
\hline Frances & 10 & 83 \\
Italiano & 1 & 8 \\
Español & 1 & 8 \\
\hline \multicolumn{1}{c}{ Total $=$} & 12 & 100 \\
\hline
\end{tabular}

Tabla 3 - Productividad idiomática de acuerdo a las referencias Archivísticas registradas en el Tratado de Documentación

Otro de los resultados que se obtuvieron de la recolección y de acuerdo a ley de Lotka, es la que tiene que ver con el número de referencia de los autores citados y la concordancia de las temáticas del área archivística que Otlet utilizo para su fundamentación. Esto se puede observar en el análisis de índice de cohesión interna en la Figura 3, donde se nota el desarrollo de la temáticas siendo la más utilizada la referente a los Métodos de organización con un total de 6 citaciones, citándose el mismo Otlet 3 veces. Los autores Muller, Freith y Fruin se encuentran citados 2 veces y a Paul Eugene Louis Fournier se cita 1 sola vez.

La segunda temática con mayor número de citaciones fue la referente a los Documentos administrativos donde citó a Edwards y Joseph Cuvelier mientras que las temáticas Administración Pública, Administradores, Fondo Documental y Valoración utilizó citaciones una sola vez en cada una de ellas. Sin embargo, es necesario resaltar que al autor Joseph Cuvelier lo citó 2 veces, una para la temática sobre el Fondo Documental y la otra para Documentos administrativos. También, cabe acotar que Joseph Cuvelier es uno de los traductores del Manual archivístico holandés al idioma francés, toda esta matematización se puede ver por el grueso de los vínculos entre los nodos de las temáticas, los nodos de los autores y los nodos de los documentos firmados por los autores. Véase figura 3.

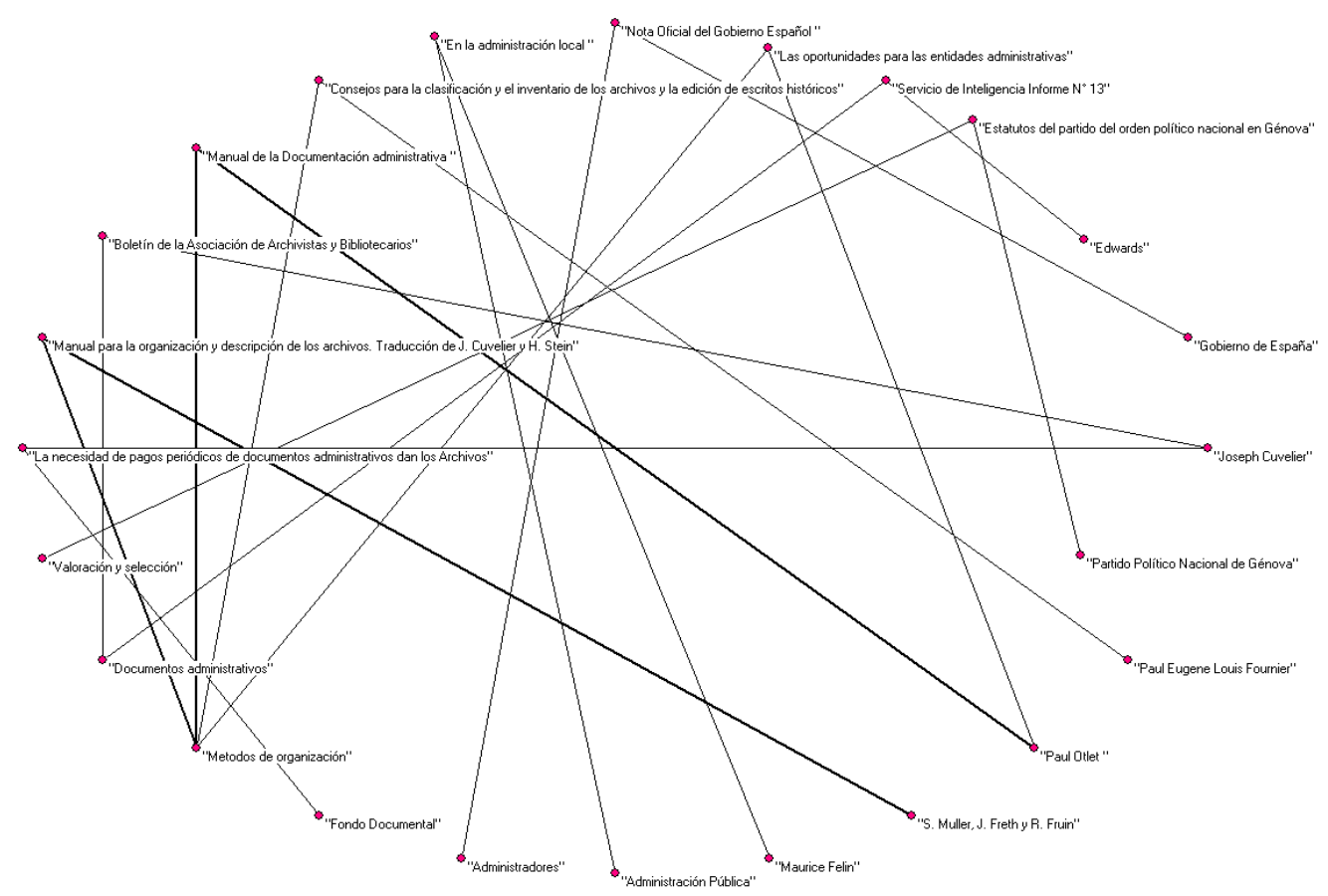

Figura 3 - Autores citados y concordancia temática de acuerdo a las referencias archivísticas registradas en el Tratado de Documentación 


\subsection{Análisis de las palabras comunes relacionadas al área de la archivística}

Según la ley de Zipf, de El Tratado de Documentación se extrajeron 407 palabras claves del ámbito archivístico las cuales se clasificaron y ordenaron, obteniendo entre estas las de mayor frecuencia, que se muestran en la Figura 4, destacándose en primer lugar la palabra Archivos con un total de 83 repeticiones, le sigue Administración con 29, Documentos con 23, Documentación administrativa con 17, Clasificación con 12 , Administraciones con 11, Documentación con 10, Colecciones con 9, Depósitos y Dossiers con 8 repeticiones cada una, Obras con 7, Colección y Papeles con 5 repeticiones cada una, 8 palabras con 4 repeticiones cada una, 7 palabras con 3 repeticiones cada una, 18 palabras con 2 repeticiones cada una y 85 palabras con una sola frecuencia.

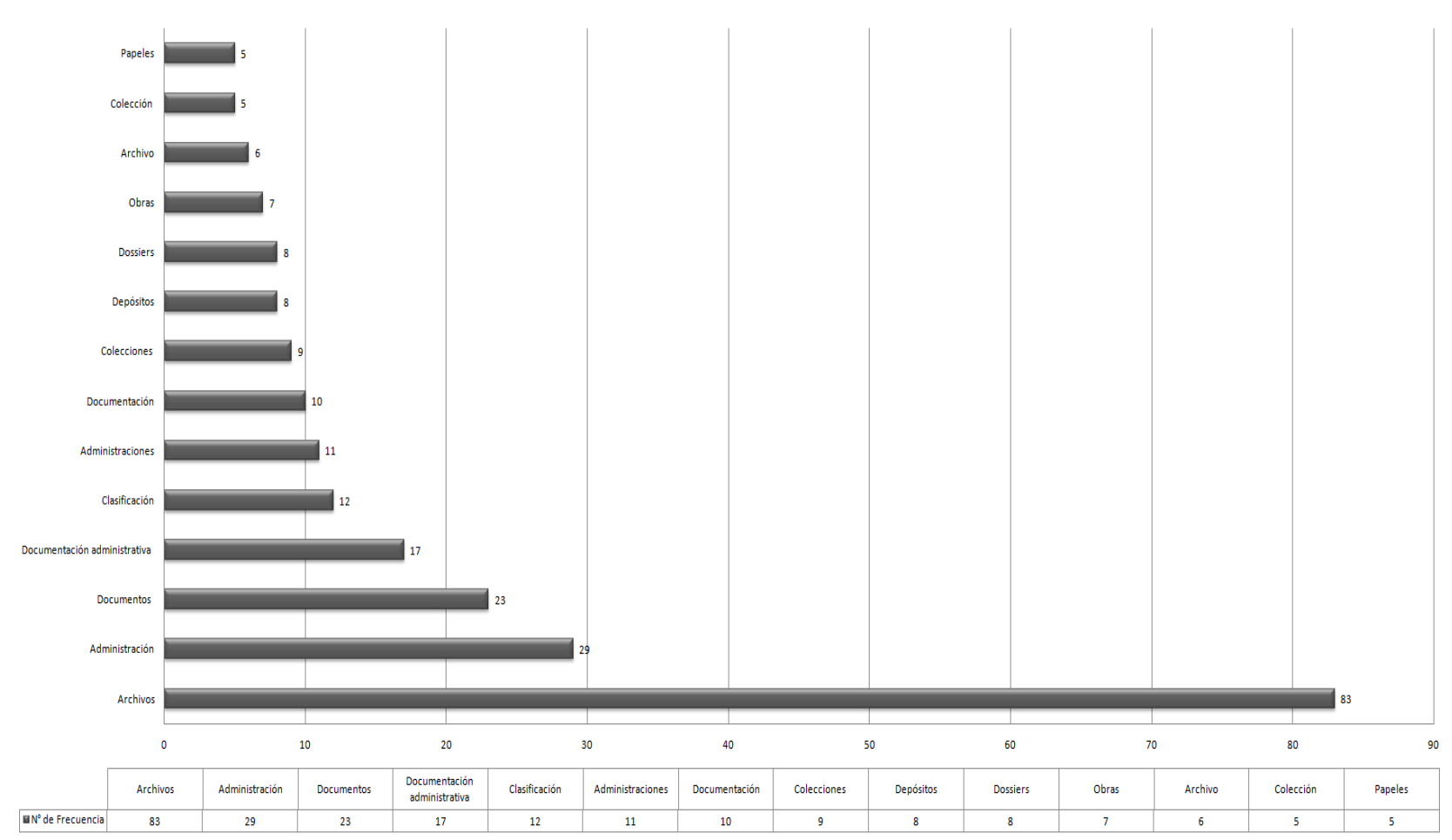

Figura 4 - Temáticas más frecuentes del área Archivística registradas en El Tratado de Documentación

En la Figura 5 se muestra un índice de cohesión externa que presenta una dimensión de la dispersión de las palabras o descriptores temáticos que bien se relacionan con la Archivística. Se aprecia que los nodos rojos palabras relacionadas- con mayor frecuencia se encuentran cerca del nodo azul -que es el actor donde se encuentran todas las palabras- mientras que los nodos rojos - palabras relacionadas- de menor frecuencia se van distanciando. Es importante destacar que para la obtención de este resultado fue necesario identificar las palabras significativas de la Archivística y la coocurrencia de palabras en el texto. 


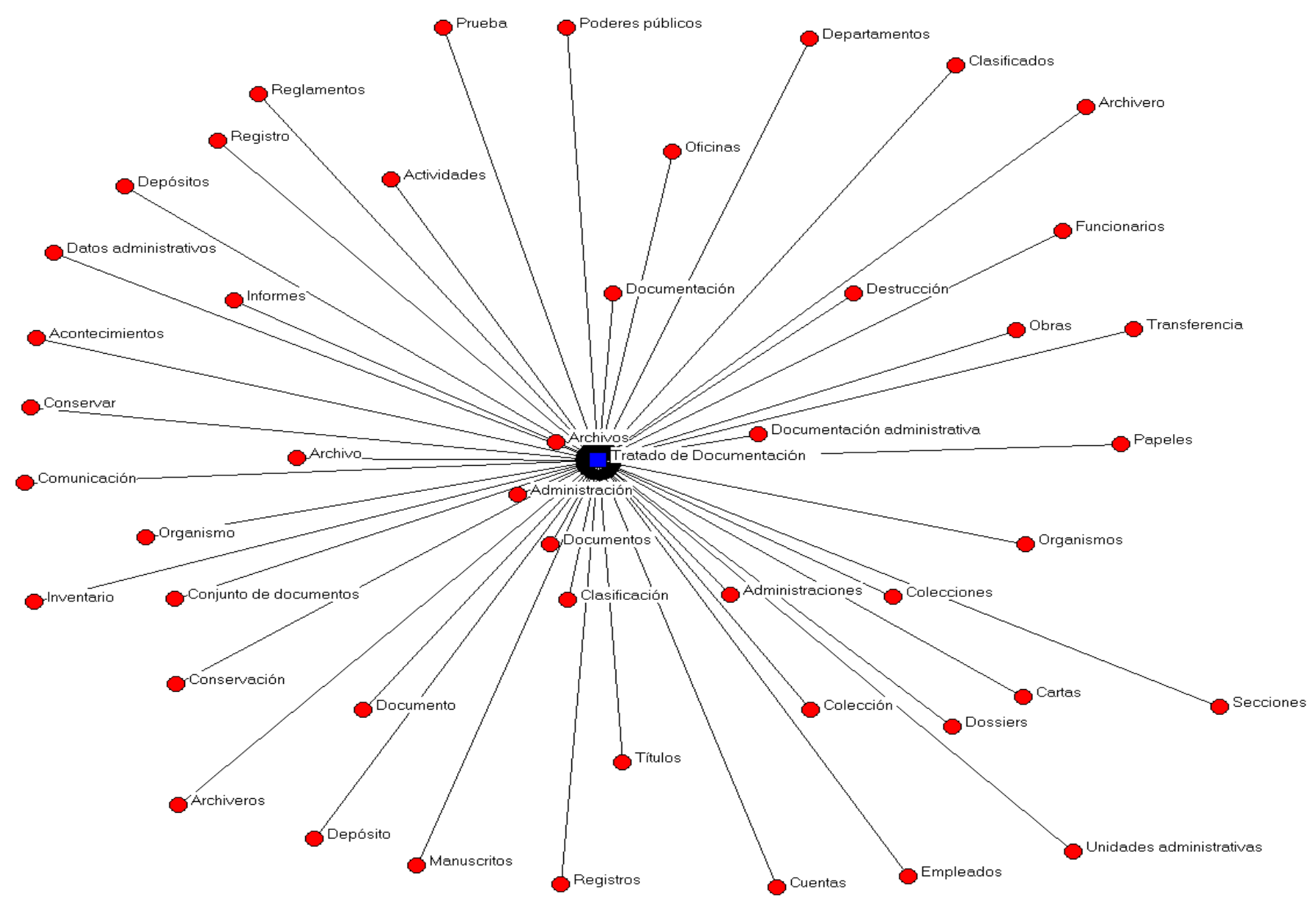

Figura 5 - Red de dispersión de palabras temáticas del área Archivística registradas en el Tratado de Documentación

\subsection{Análisis de conceptos del área archivística de acuerdo al contexto}

La concentración de las palabras descriptivas es bastante reducida del total de palabras extraídas del ámbito archivístico, la Figura 6 muestra las temáticas de esta sección. La palabra archivos se mantiene en el promedio de la densidad, mostrando que es una palabra que tiende a ser desarrollada desde tres puntos diferentes, como el conjunto de documentos, como lugar físico de preservación y como instituciones poseedoras de fuentes para la investigación histórica. Los vínculos internos reflejan la forma particular en la que se utilizó este término descriptivo, al parecer, dentro de El Tratado de Documentación han sido más enfocados al conjunto de documentos donde interactúa con temas para la administración y la historia. También se observa el tema de clasificación de los documentos, el archivo como lugar de custodia, el archivero y archiveros como profesión y asociaciones de profesionales, la Archivística como ciencia y el principio de procedencia y orden natural como reglas fundamentales para la clasificación y ordenación de los documentos de archivos. 


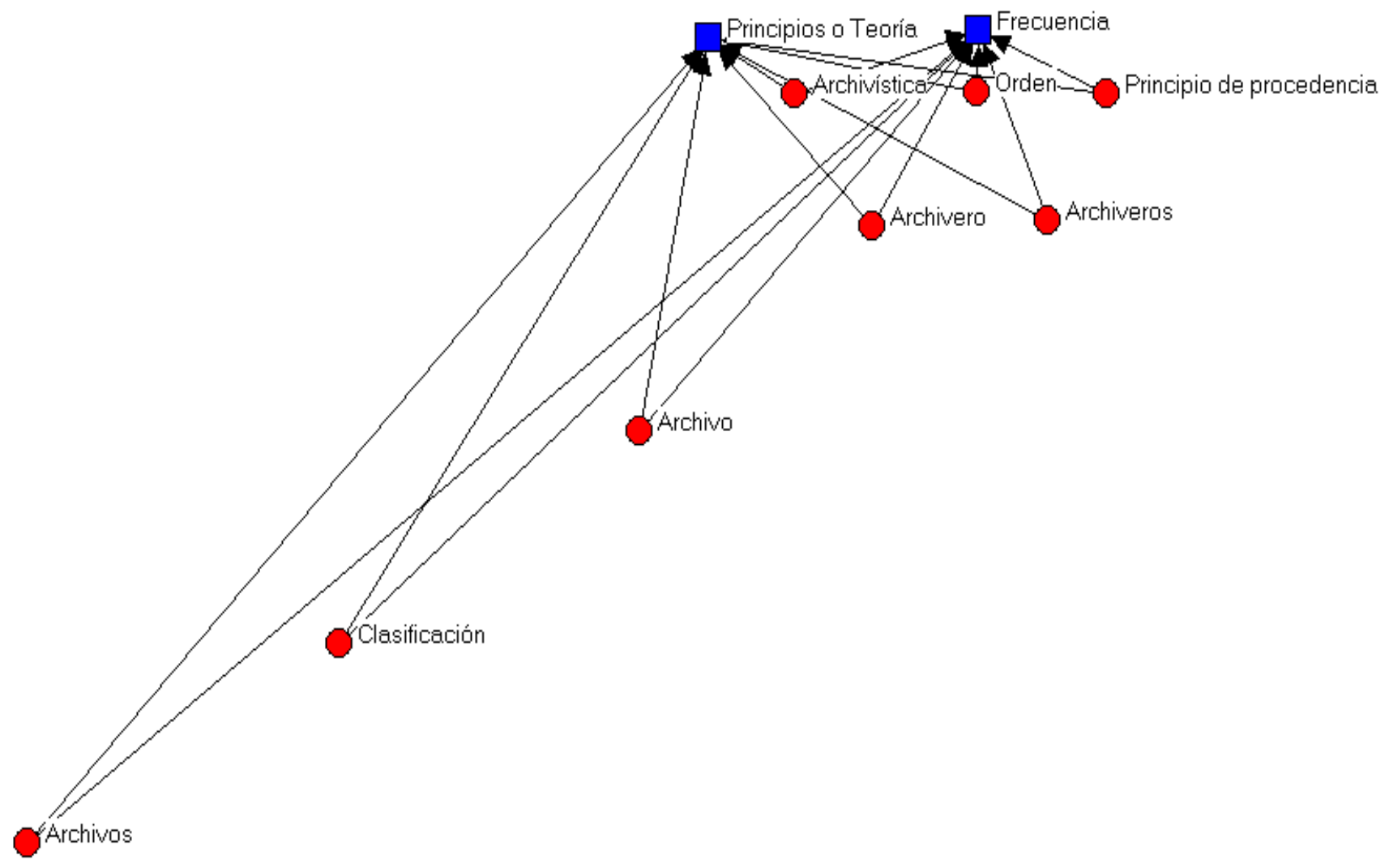

Figura 6 - Red de palabras descriptiva de acuerdo al área archivística registradas en El Tratado de Documentación

Se realizó un análisis de correspondencia simple para la tabla de contingencia de las palabras asociadas contra teoría, principios y métodos de la Archivística. Debido a la gran dispersión de los datos, se decidió agrupar teoría, principios y métodos en 15 intervalos de palabras descriptivas, que van desde Archivística, clasificación, conjunto de documentos, custodia, documento de archivo, entidad productora, evidencia, fuentes de investigación histórica, lugar físico de preservación, orden natural, organización del conjunto de documentos, principio de procedencia, profesión, usuario y valoración. En la Figura 7 se muestra el índice de cohesión externa que despliega la relación de las palabras asociadas. Este análisis provee una ubicación definitiva de las temáticas encontradas dentro de El Tratado de Documentación. Se muestra que las palabras asociadas pertenecientes a las palabras descriptivas, lo cual explicaría su densidad, siendo el tema documento de archivo la que posee más palabras asociadas que las demás temáticas. Por otro lado, las palabras asociadas con mayor frecuencia se relacionan con el temático conjunto de documentos, lo cual explica la centralidad de la temática, pues ha sido trabajada a lo largo de El Tratado de Documentación y su conexión con otros temas. 


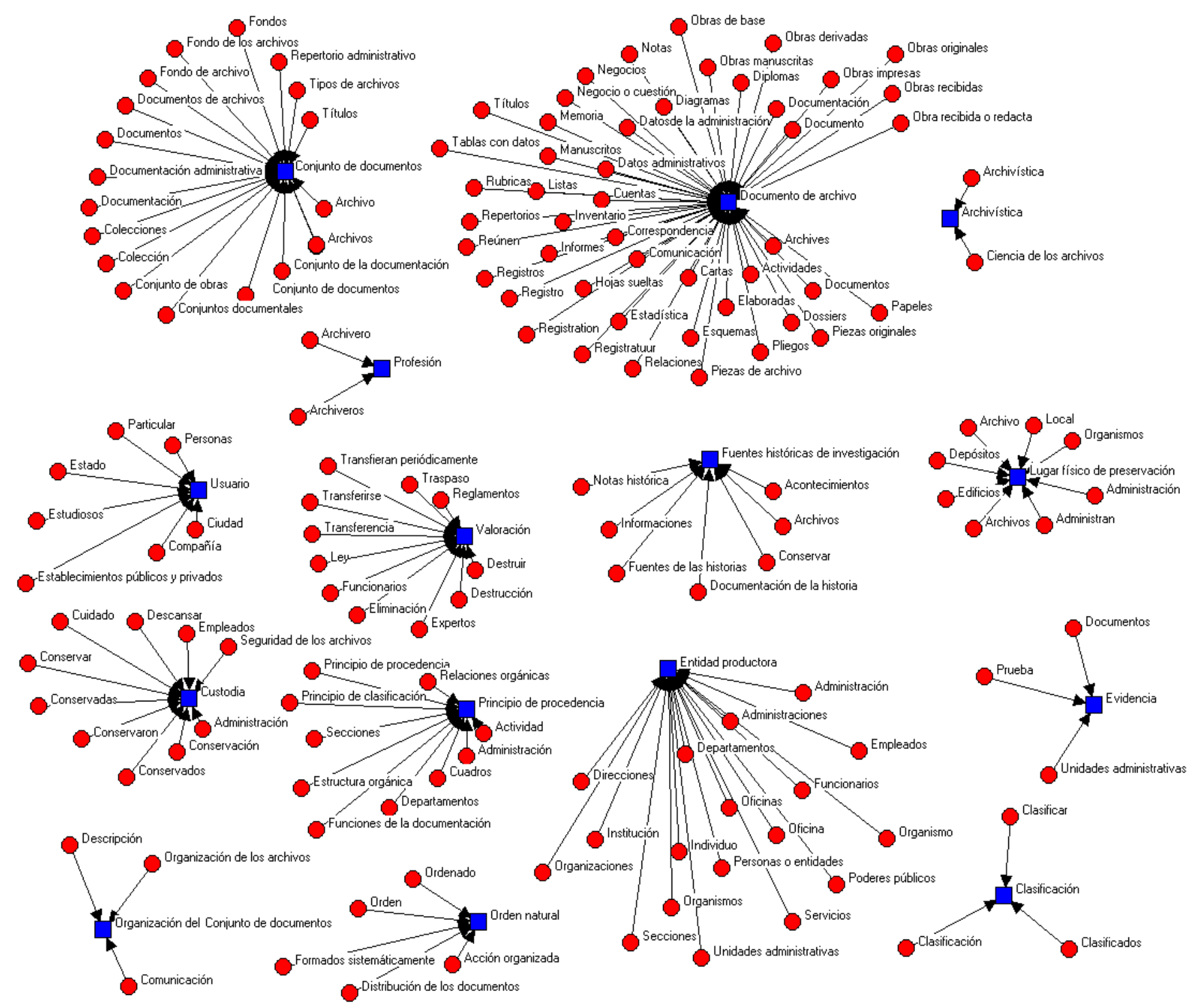

Figura 6 - Red de palabras asociadas de acuerdo al área archivística registradas en El Tratado de Documentación

\subsection{Enfoques archivísticos en El Tratado de Documentación}

Al analizar los enfoques archivísticos que se encuentran registrados en El Tratado de Documentación, se hace evidente que el mayor interés de Otlet se encuentra concentrado en los enfoques conjunto de documento y documento de archivo, sin embargo, es posible que hubiese un interés similar por el enfoque de evidencia, pero que no se vio reflejado de forma directa, sino por palabras asociativas. En todo caso, el alto número de palabras aplicadas sobre los archivos administrativos, refleja el interés que había suscitado dicho enfoque a finales del siglo XIX y comienzos del XX en Europa, en virtud de las aplicaciones del principio de procedencia y el orden natural de los documentos y el condicionamiento de los procesos de tratamientos de los archivos. Por ello no es de extrañar que la primera referencia de la Archivística sea del año 1908 y que la temática que aborde sea la del fondo documental, siendo este propuesto desde el punto de vista de la administración, pero como también Otlet estuvo influenciado por el manual holandés este concepto se asumía en los países bajos como el conjunto documentos corrientes proveniente de las administraciones en las que se custodiaban. Se puede decir que Otlet también tuvo un importante interés por otros enfoques como son la entidad productora, las instituciones como 
lugar físico de preservación, las fuentes históricas de investigación, los usuarios y el reconocimiento de la Archivística como ciencia. Esta matematización se puede apreciar en la Tabla 4.

\begin{tabular}{|c|c|c|c|c|}
\hline Teoría o concepto & Método & Principales aplicaciones & Frecuencia & $\%$ \\
\hline Conjunto de documentos & Comunicación & $\begin{array}{l}\text { Archivo, Archivos, Colección, } \\
\text { Documentación administrativa, } \\
\text { Documentos de archivos, Fondos de } \\
\text { archivo }\end{array}$ & 117 & 28,7 \\
\hline Documento de archivo & Comunicación & $\begin{array}{l}\text { Cartas, Documentos, Documentación, } \\
\text { Dossiers, Informes, Manuscritos, Papeles, } \\
\text { Registros }\end{array}$ & 97 & 23,8 \\
\hline Entidad productora & Acción & $\begin{array}{l}\text { Administraciones, Oficinas, Organismos, } \\
\text { Poderes públicos }\end{array}$ & 59 & 14,5 \\
\hline Lugar físico de preservación & Conservación & Administraciones, Archivos, Depósitos & 43 & 10,6 \\
\hline Valoración & Asignación de valor & $\begin{array}{l}\text { Destrucción, Funcionarios, Transferencia, } \\
\text { Reglamento }\end{array}$ & 18 & 4,4 \\
\hline Clasificación & Estructura organizacional & Clasificación, Clasificados, Clasificar & 15 & 3,7 \\
\hline Custodia & Conservación & Administración, conservación & 14 & 3,4 \\
\hline Principio de procedencia & Clasificación & $\begin{array}{l}\text { Administración, Departamentos, } \\
\text { Estructura orgánica, Principio de } \\
\text { clasificación, Secciones }\end{array}$ & 10 & 2,5 \\
\hline Fuentes históricas de investigación & Histórico & $\begin{array}{l}\text { Acontecimientos, Documentos de la } \\
\text { historia, Fuentes históricas, Información }\end{array}$ & 9 & 2,2 \\
\hline Usuario & Fuentes de información & Estudiosos, Estado, Personas & 7 & 1,7 \\
\hline Orden natural & Ordenación de los documentos & Distribución de documentos & 5 & 1,2 \\
\hline Evidencia & Valides & Prueba, Testimonio & 4 & 1,0 \\
\hline Profesión Archivistica & Conocimiento & Archiveros & 4 & 1,0 \\
\hline Organización del fondo documental & Estructura organizacional & Organización de los archivos & 3 & 0,7 \\
\hline Archivistica & Cientifico técnico & Ciencia de los archivos & 2 & 0,5 \\
\hline
\end{tabular}

Tabla 4 - Red de palabras asociadas de acuerdo al área Archivística registradas en El Tratado de Documentación

\section{Conclusiones}

El análisis bibliométrico de palabras asociadas funcionó como herramienta para encontrar los resultados alcanzados en la investigación. En tal sentido, el software UCINET y sus paquetes gráficos NetDraw y PAJEK permitieron mostrar cada una de las redes de relaciones entre términos, haciendo más fácil el análisis de tipo temático.

Los resultados de la aplicación del estudio bibliométrico permitieron describir los enfoques sobre archivística que aparecen en El Tratado de Documentación. Así se pudo determinar que los temas encontrados tienen centralidad y baja densidad. El tema más especializado tiene que ver con la documentación administrativa y el conjunto de documentos como fuentes de información para la investigación histórica. Los temas relacionados con los usuarios, el orden natural, la evidencia y la organización de los fondos documentales pueden considerarse como los menos desarrollados en El Tratado de Documentación.

Del campo de la Archivística, los temáticos documentos de archivo y conjunto documental son las más utilizadas en El Tratado de Documentación, encontrándose diseminadas en los apartados; fundamento, bibliología y el libro y el documento. 
Las temáticas del campo Archivístico que se encuentran más asociadas en El Tratado son: entidad productora y lugar físico de preservación, aunque aparecen con menores intervalos de citación.

El análisis de correspondencia simple de contingencia de palabras asociadas para la teoría, los principios y los métodos de la Archivística, muestran los enfoques desarrollados por los autores de la Archivística clásica que Otelt consideró para desarrollar su discurso. Estos aparecen analizados en el índice de cohesión exterior.

\section{Bibliografía}

Otlet, P. M. (2004). El Tratado de Documentación: el libro sobre el libro: teoría y práctica, traducción de María Dolores Ayuso García. La Habana: Félix Valera. (Trabajo original publicado en 1934).

(2008). On the cultural and intellectual context of European Documentation in the early twentieth century. Chapter 2, pp 44-57, in: European Modernism and the Information Society, ed. W. Boyd Rayward. Aldershot, UK: Ashgate. Recuperado el 29 de Julio de 2013 de http://people.ischool.berkeley.edu/ buckland/modcontext07.pdf

Thomassen, T. (1999). The development of archival science and its european dimension: in The Archivist and the Archival Science. Seminar for Anna Christina Ulfsparre, (Lund: Landsarkivet, 1999). Recuperado el 29 de Julio de 2013, del sitio Web de Zagreb Society Archives: http://daz.hr/zad/arhol/the-development-of-archivalscience-and-its-european-dimension/

\section{Datos del autor}

\section{Leomar José Montilla Peña}

Máster en Bibliotecología y Ciencias de la Información. Egresado de la Universidad de la Habana, Faculta de Comunicación, La Habana, Cuba. Licenciado en Bibliotecología y Ciencias de la Información por la misma universidad. Encargado de la Biblioteca Especializada del Instituto Nacional de Investigaciones Agrícola, Unidad Ejecutora Lara, Venezuela. Profesor del Programa Nacional de Formación en Ciencias de la Información en la Universidad Politécnica Territorial de Lara Andrés Eloy Blanco, Barquisimeto, Venezuela. Integrante del Comité Interinstitucional para el Fortalecimiento de la Gestión del Programa Nacional de Formación en Ciencias de la Información, Ministerio del Poder Popular para la Educación Universitaria, Caracas, Venezuela.

\section{leomonp@gmail.com}

$\begin{array}{ll}\text { Recibido-Received } & : 2013-06-09 \\ \text { Aceptado-Accepted } & : 2013-12-30\end{array}$

\section{$(\mathrm{cc})$ EY}

This work is licensed under a Creative Commons Attribution 4.0

United States License.

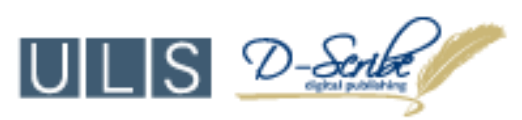

This journal is published by the University Library System of the University of Pittsburgh as part of its D-Scribe Digital Publishing Program and is cosponsored by the University of Pittsburgh Press. 